\title{
Investigating Responses to Compliments by Brazilian Portuguese Speaking EFL Learners: A Contrastive Analysis
}

\author{
Marisa de Lima Zanella \\ College of Education, Humanities and Social Sciences, Al Ain University of Science and Technology, P.O.Box: 64141 Al Ain, UAE \\ E-mail:201510748@aau.ac.ae
}

Doi:10.7575/aiac.alls.v.8n.1p.215

Received: 09/12/2016

URL: http://dx.doi.org/10.7575/aiac.alls.v.8n.1p.215

Accepted: 18/02/2017

\begin{abstract}
This paper reports a study on politeness strategies of Brazilian Portuguese speakers and American English speakers regarding their responses to compliments. The aim of this research is to gain an insight into the politeness characteristics of Brazilian Portuguese speakers by analyzing how Brazilian students react when receiving compliments. It also aims to investigate how politeness from Brazilian Portuguese speakers differs from politeness of American English speakers when receiving compliments. The population for this research consists of 12 students with intermediate and upper-intermediate levels of EFL from the Cooperative de Trabalho Magna, a private school in Brazil. The study followed a descriptive and interpretive qualitative research method, where 133 answers were analyzed and then contrasted with Chen's (1993) study of politeness strategies between American English and Chinese speakers. This study shows that, unlike American English speakers, Brazilian Portuguese speakers need to justify and give reasons for the compliment received.
\end{abstract}

Keywords: Brazilian Politeness, Brown and Levinson's politeness theory, receiving compliments

\section{Introduction}

The advance of technology, with the widespread use of the Internet and social media, has created a dynamic world and increased communication among nations. World globalization has encouraged cultural exchanges; this demands from us a certain commitment to understanding different cultures, flexibility to analyze, and filtering information. In this context, Brown and Levinson's (1978) politeness theory is still widely used to elucidate human social interaction. Many transformations have occurred in the world, and the desire of belonging to a certain social group reminds us of the importance of preserving self-image.

Brazil is a huge country with a mix of cultures, including Europeans, Africans, Asians, and Arabs, as well as native Brazilians. The country is divided into five regions; each region has its own cultural traditions, “...for the specificities of the Brazilian culture are extremely distinct when considering regions, tribes and even organizations" (Moraes et al., 2016, p. 87). However, Brazilians are well known for the "Jeitinho Brasileiro" which translates into "the Brazilian way" in English, which has been explored by many Brazilian scholars such as Vieira et al. (1982), Massukado-Nakatani et al. (2009) and Moraes et al. (2016). Brazilians inherit from the Portuguese crown the idea of social castes, with each individual needing to reach a higher status to be appreciated by society. This legacy of the "Jeitinho" reflects on the way Brazilian Portuguese speakers act when receiving a compliment. Oliveira (2016) observes that "reflecting upon Brazilian politeness means invoking certain blindness to faces" (p. 5). Although culturally unique, Brazilian Portuguese speaker responses to compliments has been barely explored. Moreover, to the best of our knowledge, no study has been done on politeness by reproducing exactly the same questionnaire of Chen's (1993) seminal paper. Therefore, this paper aims to shed light upon the idea of Brazilian politeness by analyzing how Brazilian students react when receiving compliments in four different given situations (see figure1). It also aims to investigate how politeness of Brazilian Portuguese speakers differs from politeness of American English speakers when receiving compliments.

This paper is organized as follows: Section 2 presents a brief review of the literature, and Section 3 states the research methodology of the paper. This is followed by Section 4, which analyzes the data and interprets the findings, while the final section presents the conclusion.

\section{Literature Review}

Five important concepts serve as a base for this study, namely Pragmatics, Politeness Theory, Positive Politeness, Negative Politeness, and Compliments. What follows is a brief review of these concepts with illustrative examples from Brazilian Portuguese speakers.

Kuiper and Allan (2010, p. 20) define pragmatics as the study of the way in which the context contributes to meaning. Yule (1996) states that "pragmatics is the study of the relationships between linguistic forms and the users of these forms" (p. 4). Pragmatics is related to the way an individual expresses his/her thoughts in different situations to be understood or convey a specific meaning. The same utterance or sentence can be used in different situations and 
consequently has different meanings, depending on the context. For instance, "Obrigado(a)" translated to English means "thank you." However, it depends on the context within which the word is used. It can express gratitude or it also can express irony. Another example: "Como está frio," which can be understood as a comment about how cold the weather is, or it also can be interpreted that the speaker is feeling cold. The interpretation of the message depends on the context, and the intonation of the speaker.

Leech (1983, p. 82) defines politeness as forms of behavior that establish and maintain social harmony. Brown and Levinson (1978) state that politeness strategies are developed to "save face", meaning the respect that each individual has for him/herself, and maintaining that "self-esteem" in public or in private situations (pp. 73-76). By nature, humans try avoid embarrassing themselves or others, or making anyone feel uncomfortable in social situations. Brown and Levinson (1978) also classified politeness accordingly on the human behavior: Bald on Record, Negative Politeness, Positive Politeness, and Off-Record-Indirect.

Humans by nature cannot live alone. Every one of us seeks to be part of a group, have friends and be accepted by society. There is an innate desire to achieve social and economic stability in order to succeed in life and feel good about ourselves. The type of society we live in can determine the individual's lifestyle, religion, politics, etc. Every group has its own way of seeing and reacting to situations in life, and it is in this way that politeness theory comes to play an important role. The social group determines the way a person react to a simple situation; for example, when asking for water:

- "Quero água" means "I want water."

- "Me dá água" means "Give me water."

- "Me dá uma água por favor" means "Give me some water, please."

- "Desculpa por incomodá-lo, mas você poderia me dar uma água por favor?" means "I am sorry for bothering you, but could you please give me some water?"

- "Estou com sede" means "I'm thirsty."

Those examples above showed how Brazilian Portuguese speakers can adjust themselves in different social occasions to satisfy their need for water. It can be in a form of request, an order, a hint, or even a request for approval.

According to Brown and Levinson (1978, p. 101), with the positive politeness strategy, the speaker recognizes that the hearer has a desire to be respected. The speaker seeks to minimize any disrespect to the hearer's face and tries to make the hearer feel good about themselves. Positive politeness confirms a friendly relationship where the group acceptance and reciprocity is necessary to maintain the group social relationship. For example: "What a beautiful vase this is! Where did it come from?" (Brown \& Levinson 1978: 103). This example shows friendship and interest in the same object, the vase. Positive politeness is used when a strong friendship exists. Positive politeness is a way of showing a strong social relationship with and appreciation for the other. For example, it is reflected in a compliment to a classmate: "Your presentation was amazing!" It also minimizes conflicts or any other problems in the relationship by seeking agreement. Akutsu (2009) pointed out that it is important that EFL learners know and use positive politeness strategies when necessary to develop good interpersonal relationships.

On the other hand, Brown and Levinson (1987) noted situations of "negative face as the addressees want to have his freedom of action unhindered and his attention unimpeded by others" (p. 312). Negative politeness strategy also expresses the speaker's recognition of the hearer's feelings by avoiding being invasive. The speaker keeps a social distance from the hearer. It occurs when there is not a close relationship. An example of negative politeness can be seen at the airport, when they announce a gate number or flight delay. The announcement normally starts with the phrase: "May I have your attention please..." It is a polite way of imposing upon or asking someone to perform the action that the speaker desires from the hearer. For example: "Desculpa o incômodo, mas será que eu poderia abir a janela?" means "I'm sorry to bother you but I just wanted to ask you if I could open the window?"

Holmes (1986) defines compliments as speech acts which are used explicitly or implicitly to praise positive characteristics, skills, or possessions of the addressee that are appreciated by the speaker or the entire community. Brown and Levinson (1987) propose that compliments are positive politeness strategies addressed to the hearer's positive face to show that the speaker is aware of the hearer's need. Compliments can seem as Face Threatening Acts (FTAs) when the speaker uses the compliment to obtain privileges or something that belongs to the hearer. Jing and Liying (2005) mention that speakers of different languages differ in their responses to compliments. According to Yu (2005), compliments are very complex, because a compliment can function both as a positive or negative politeness device. For instance, for Brazilian Portuguese speakers, it is common to hear a man compliment a woman's look, "Você tá linda hoje!" or "You look beautiful today!" However, it can be interpreted as either a positive or negative compliment depending on the intonation of the speaker, and the way it is delivered to the hearers. The compliment can be given in a way that improves the hearers' self-esteem, or it can be given in a sarcastic way that denigrates the hearers' self-esteem.

Politeness is part of our daily life, and it is inevitable to pay compliments on a daily basis when individuals live in a dynamic society. It can be given to a friend, coworker, family members, etc. Nevertheless, a compliment can be accepted or rejected depending on the situation and the cultural boundaries. What is accepted in one culture does not necessarily fit in another culture. The way people interact by using compliments has been a vast camp of study in many 
cultures like Chinese, Persian, British, Japanese, Malaysian, Canadian, American, etc. This research aims to contribute to the field by analyzing how Brazilian Portuguese speakers respond to compliments.

\section{Methodology}

This study followed a descriptive and interpretive qualitative research method. Creswell (2007, p. 4) states that qualitative research is about exploring and understanding the means of individuals or groups in relation to a social context. The research design is a comparative case-study focused on high-school students. The questionnaire was designed to address only four situations in which compliments can occur, i.e., looks, clothes, achievement, and possession. However, this was a deliberate choice to allow comparability between the two surveys.

The sample for this research consists of students from the Cooperativo de Trabalho Magna, a private school in Brazil, located in the state of Santa Catarina and the city of Concordia. The sample included 12 students: four females and eight males, all native Brazilian Portuguese speakers. The research focuses on students with an intermediate and upperintermediate level of EFL to obtain reliable data. Reading comprehension is a skill that requires mastery of upper EFL levels so the students can understand the questions properly and thus eliminate language barriers that can deeply affect the results of the research. In this regard, Pang (2008, p. 5) notes that a second-language reader's linguistic proficiency is a significant factor that constrains the reader's text comprehension.

The participants of the research were asked to answer an open questionnaire designed by Chen (1993). The questionnaire contains four conventional situations where compliments were used, and allows the students to answer the questions in their own words. Participants completed the questionnaire during an English class to ensure they fully understood the questions.

\section{Data Analysis}

The total data collected included 133 responses and are categorized according to the following strategies:

- Thanking: This is a routine use to express gratitude or to end a conversation. The meaning can be differentiated by analyzing the situation in which it is used and the degree of relationship between the complimented and the complimenter. Example in Situation 3 of the applied questionnaire: "That was a great presentation. I really enjoyed it." The reply was: "Thanks".

- Agreeing: The hearers accept the compliment and avoid boasting about themselves. Example in Situation 3 of the applied questionnaire: "That was a great presentation. I really enjoyed it." The reply was: "You are so kind! Thanks."

- Expressing gladness: The complimented person shows appreciation for the compliment received. Example in Situation 4 of the applied questionnaire: "Wow! What a watch! I wish I had one like that." The reply was: "I'm glad you noticed."

- Joking: This is a technique used by the speaker to make the hearers relax. Here, the speaker and hearer need to share the same background and have a close relationship. Example in Situation 1 of the applied questionnaire: "You look so nice! Even nicer than when I saw you last time." The reply was: "Thanks! I looked horrible that time."

- Thanking and returning the compliment: This is a strategy that involves initial acceptance of the compliment, plus praising the complimenter in return. It demonstrates an intention to maintain a good relationship. Example in Situation 2 of the applied questionnaire: "What a nice sweater! You look great in it." The reply was: "Thanks! I like your sweater too!"

- Offering Object of Compliment or Help: The complimented person feels compelled by the compliment received and offers the object of the compliment to the complimenter. Example in Situation 2 of the applied questionnaire: "What a nice sweater! You look great in it." The reply was: "Want me to take you to the shop?" or "If you want, you can borrow it."

- Encouraging: The complimented person inspires the complimenter to achieve or obtain the same object of the compliment. Example in Situation 4 of the applied questionnaire: "Wow! What a watch! I wish I had one like that." The reply: "I hope one day you have one like that." and "Haha, you should save up!"

- Explaining: The hearers accept the compliment and add an explanation about the item being complimented by adding information about it. Example in Situation 2 of the applied questionnaire: "What a nice sweater! You look great in it." The reply: "Thank you, my grandmother bought it for me."

- Doubting: The complimented person responds with a question that indicates doubt about the intention or sincerity of the compliment. Example in Situation 2 of the applied questionnaire: "What a nice sweater! You look great in it." The reply: "Do you like it? I bought it yesterday."

- Rejecting: The complimented person disagrees with the compliment received. The hearer treats the compliment as exaggeration or irony from the complimenter. Example in Situation 3 of the applied questionnaire: "That was a great presentation. I really enjoyed it." The reply: "Thank you, but I think that your presentation was better than mine." 
Agreeing, 5.2

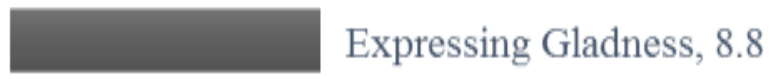

Joking, 2.9

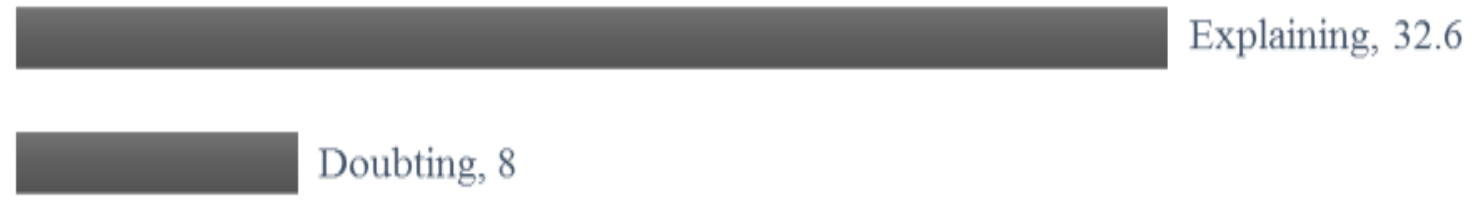

Rejecting, 1.5

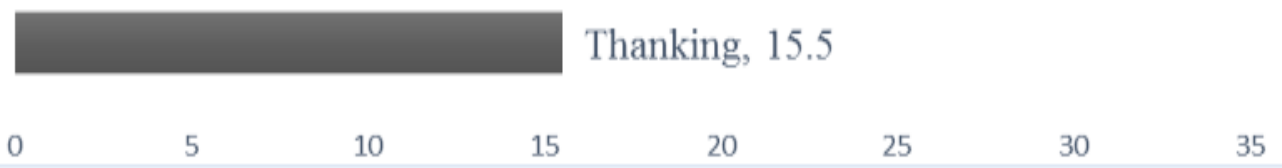

Figure 1. Percentages of Strategies Used by Brazilian Portuguese Speakers When Receiving Compliments

By analyzing the figure above, it gives some evidences that Brazilian Portuguese speakers cannot receive a compliment for granting; they tend to want to explain it. For example, in Situation 2: "What a nice sweater! You look great in it." The most common answer was: "I bought it at the mall/yesterday," so that $31.6 \%$ of the answers given were classified as explaining strategy. Thanking and returning the compliment comes in second with $19.12 \%$, followed by the thanking strategy with $15.5 \%$. These three strategies combined give a weight of $66.22 \%$ of the total answers. Expressing gladness and doubting ranked $8.85 \%$ and $8 \%$ respectively. Agreeing constituted 5.2\% of the answers, while offering help to the object of the compliment and encouraging have the same score of 3.6\%. The least-used strategy used by Brazilian Portuguese speakers is rejecting compliments, with only $1 \%$ of the total answers.

By cross-analyzing the data from Chen's research, it is possible to see the cultural differences between Brazilian Portuguese speakers and American English speakers when receiving a compliment (see Table 1 below). Brazilian Portuguese speakers need to justify and give reasons for the compliment received. Take as an example Situation 3: "That was a great presentation. I really enjoyed it." An example of a typical reply was: "Thanks, it took me a long time to prepare it." Figure 1 shows that $32.6 \%$ of the answers given by Brazilian Portuguese speakers are of the explaining strategy, while only $23.30 \%$ of American English speakers used that strategy. Indeed, Brazilian Portuguese speakers explain 39.9\% more than American English speakers when receiving a compliment. Such a contrast can be considered as related to Brazilian cultural boundaries, as Brazil is based on a family-oriented society (Carlo et al., 2007). It is normal for single young adults to live with their parents, which implies the role of obedience and submission to elders, while in America more young adults live on their own, since their economic situation is usually better than in Brazil.

Another fact that supports the relevance of cultural boundaries, such as a family-oriented society, to the politeness theory is that only $1.5 \%$ of Brazilian Portuguese speakers reject a compliment. The low indices of rejection of compliments by the Brazilians could be related to the way Brazilians are raised. On the other hand, $12.70 \%$ of American English speakers reject compliments. That is a significant percentage of $84.67 \%$ more rejection of compliments than Brazilian Portuguese speakers. Oliveira (2015) states that American culture is more oriented towards individualism. This individualism can be observed with the thanking strategy as well. American English speakers use it $29.50 \%$ of the time, while Brazilian Portuguese speakers use it only $15.50 \%$ of the time. Americans give a simple "thank you" $47.46 \%$ times more than Brazilian Portuguese speakers. Such a brief response is a simple way of being polite and does not offer a chance to improve the relationship between the two parties.

American English speakers use negative politeness more than positive politeness in those situations. On the other hand, Brazilians are well known for their cordiality which can be related to the positive politeness strategies. Brazilians like to make new friends, especially with foreigners. Brazilian Portuguese speakers do not see a language as a communication barrier but rather as an opportunity to amplify friendly relationships. Teixera and Andrade (2009, p. 38) found that 
$79.3 \%$ of the international students from the Universidade Federal do Rio Grande do Sul (UFRGS) has little difficulty in establishing friendships with other Brazilians. Boozer (1971, p. 295) emphasized that the Brazilian national character is warm and tolerant. This can be observed as well via the following strategies; thanking and returning compliment, offering object of the compliment or help and encouraging; Brazilian Portuguese speakers use these strategies more than American English speakers. Those three strategies give the opportunity to carry on a conversation and greatly increase the opportunity to become friends. Boozer (1971, p. 295) stated that Brazilians highly value their personal relationships. The informal way in which Brazilian Portuguese speakers address hearers must be highlighted as one of the most important differences between the two cultures. Brazilian politeness depends on the context, and if an American speaker has not acknowledged the differences between both cultures, it can lead to misunderstanding between members of the two cultures. Although Chen's (1993) seminal paper is highly cited and comparatively reproduced against many other language speakers, to the extent of our knowledge there is no other work which exactly reproduces Chen's study for Brazilian Portuguese speakers.

Table 1. Brazilian Portuguese Speakers vs. American English Speakers: Compliment Strategies

\begin{tabular}{lll}
\multicolumn{1}{l}{ Strategies } & Brazilians & Americans \\
\hline Thanking & $15.50 \%$ & $\mathbf{2 9 . 5 0 \%}$ \\
Agreeing & $5.20 \%$ & $2.95 \%$ \\
Expressing gladness & $8.80 \%$ & $3 \%$ \\
Joking & $2.90 \%$ & $3.83 \%$ \\
Thanking and Returning Compliment & $19.12 \%$ & $14.50 \%$ \\
Offering Object of Compliment or Help & $3.60 \%$ & $2.60 \%$ \\
Encouraging & $3.60 \%$ & $1.40 \%$ \\
Explaining & $\mathbf{3 2 . 6 0 \%}$ & $23.30 \%$ \\
Doubting & $8 \%$ & $6.20 \%$ \\
Rejecting & $1.50 \%$ & $12.70 \%$ \\
\hline
\end{tabular}

\section{Conclusion}

The aim of this research was to compare politeness strategies between a population sample from the US and Brazil. A common basis to allow comparability was obtained by replicating the exact same questions of Chen (1993) questionnaire. After reviewing the different strategies of politeness as per Brown and Levinson (1987), thus categorizing the respondents' possible answers, the paper lays out some typical expressions used by Brazilians that reflect the language structure and cordiality. The survey was applied for Brazilian students with upper levels of English. All students were enrolled in Cooperativa de Trabalho Magna, city of Concordia (RS), Brazil. A total of 133 responses were obtained and categorized accordingly with the 10 defined strategies. The main difference between Brazilian Portuguese speakers and American English speakers are that Americans show higher rates of either thanking or rejecting compliments, while Brazilians show higher rates of explanation. These results corroborate expected cultural differences that should be further explored in future studies, especially considering that Brazil is a mix of cultures. In order to have a better representation of the politeness strategies from Brazilian Portuguese speakers, the five regions of Brazil should be represented. In addition, examining the use of euphemistic expressions by Portuguese EFL learners (see Altakhaineh \& Rahrouh's 2015 study for further information about this phenomenon) is an area worthy of investigation.

\section{Acknowledgments}

The author is grateful to Dr. Abdel Rahman Altakhaineh for his insightful and constructive comments on early drafts of the paper. Many thanks also go to Miss Tania Regina Forner, from the Cooperativa de Trabalho Magna, who used her teaching time to apply the questionnaire. The author is thankful to the students who took part in the survey. Any remaining errors are my own.

\section{References}

Akutsu,Y. (2009). Positive Politeness Strategies in Oral Communication I Textbooks - Focusing on Terms of Address-. The Economic Journal of Takasaki City University of Economics, 52, 59-70.

Altakhaineh, A.R.M., \& Rahrouh, H.N. (2015). The use of euphemistic expressions by Arab EFL learners: Evidence from Al Ain University of Science and Technology. International Journal of English Linguistics, 5(1), 14-21.

Brown, P., \& Levinson, S. (1987). Politeness: Some universals in language usage. Cambridge: Cambridge University Press.

Boozer, M. (1971). Developing Human Communities: A Brazilian Experience. The Crisis A Record of The Darker Race, 78(9), 293-298. 
Carlo, G., Koller, S., Raffaelli, M., \& Guzman, M. (2007). Culture-Related Strengths Among Latin American Families: A Case Study of Brazil. Marriage \& Family Review, 41 (3-4), 335-360.

Chen, R. (1993). Responding to compliments A contrastive study of politeness strategies between American English and Chinese speakers. Jornal of Pragmatics, 20, 49-75

Creswell, J. W. (2007). Research design: Qualitative, quantitative, and mixed methods approaches. Los Angeles: SAGE Publications, Inc.

Holmes, J. (1986). Compliments and compliment responses in New Zealand English. Anthropological

Linguistics, 28(4), 458-508.

Jing, Q., \& Li-ying, W. (2005). Pragmatic Transfer in Compliment Responses by Chinese Learners of English. Paper presented at the Australia Association in Research for Education Annual Conference, Pramatta, Australia.

Kuiper, K., \& Allan, W. S. (2010). An Introduction to English Language Word, Sound and Sentence Houndmills, Basingstoke, Hampshire: Palgrave Macmillan.

Leech, G. (1983). Principles of pragmatics. London: Longman

Moraes, A.F., Gomes, D.C., \& Helal, D.H. (2016). Brazilian Jeitinho and Culture: An Analysis of the Films Elite Squad 1 and 2. Revista de Administracao Mackenzie, 17 (3). doi.org/10.1590/1678-69712016/administracao.v17n3p84-104.

Massukado-Nakatani, M. S., Mussi, F.M., \& Pedroso, J.P.P, (2009). A relação entre o jeitinho

brasileiro e o perfil empreendedor: possíveis interfaces no contexto da atividade empreendedora no Brasil. Revista de Administracao Mackenzie, 10 (4), 100-130.

Oliveira, J. Pragmatics of Brazilian Politeness. Academia.edu (Online). Available: http://www.academia.edu/3748656/Pragmatics_of_Brazilian_Politeness [Accessed 4 November 2016]

Oliveira, M. M .(2015). Assertiveness, Compliance and Politeness: Pragmatic and Sociocultural Aspects of 'Brazilian English' and American English. International Journal of Society, Culture \& Language (online) Available: http://www.ijscl.net/article_11538_6d869701a685e45195a77f7803b693b5.pdf [Accessed 15 December 2016]

Pang, J. (2008). Research on good and poor reader characteristic: Implication for L2 reading research in China. Reading in a Foreign Language, 20(1), 1-18.

Teixeira, M.A.P., \& Andrade, A.M.J. (2009). Adaptação à universidade de estudantes internacionais:

Um estudo com alunos de um programa de convênio. Revista Brasileira de Orientação Profissional, 2009, 10(1), 3344.

Vieira, C. A., Costa, F. L., \& Barbosa, L. O. (1982). O "jeitinho" brasileiro como um recurso poder. Revista de Administração Pública, 16(1), 5-31. (Online) Available:

http://www.spell.org.br/documentos/ver/15128/o--jeitinho--brasileiro-como-um-recurso-de-poder [Accessed November 2016]

Yu, M. (2005). Sociolinguistic Competence in the Complimenting Act of Native Chinese and American English Speakers: A Mirror of Cultural Value. Language and Speech, 48 (1), 91-119

Yule, G. (1996). Pragmatics. Oxford University Press.

\section{Appendix 1: Questionnaire}

Directions: Please respond to the following situations. For each situation, you might find more than one response socially appropriate. In that case, please write all of them in the lines provided.

1. You meet an acquaintance you haven't seen for some time. After an exchange of greetings, she/he says: "You look so nice! Even nicer than when I saw you last time". To this, you reply:

A:

B:

C:

D:

2. You are wearing a sweater. One of your friends meets you in the morning and says: "What a nice sweater! You look great on it". You reply:

A:

B:

C:

D:

3. You have given a presentation in your biology class. After the presentation one of your classmates comes to you and says: "That was a great presentation. I really enjoyed it". You reply:

A:

B:

C:

D:

4. You are wearing a Rolex watch. A friend of yours sees it and says to you: "Wow! What a watch! I wish I had one like that". You reply:

A:

B:

C:

D: 